\title{
The Nutritional Value of Traditional Syrian Sweets and Their Calorie Density
}

\author{
Louay Labban ${ }^{1, ~ *}$, Nasser Thallaj ${ }^{1}$, Mohammad Al Masri ${ }^{2}$ \\ ${ }^{1}$ Faculty of Pharmacy, Al Jazeera Private University, Damascus, Syria \\ ${ }^{2}$ Faculty of Agriculture, Al Baath University, Homs, Syria
}

Email address:

drlouay@gmail.com (L. Labban)

${ }^{*}$ Corresponding author

To cite this article:

Louay Labban, Nasser Thallaj, Mohammad Al Masri. The Nutritional Value of Traditional Syrian Sweets and Their Calorie Density. World Journal of Food Science and Technology. Vol. 3, No. 4, 2019, pp. 40-47. doi: 10.11648/j.wjfst.20190304.11

Received: November 20, 2019; Accepted: December 9, 2019; Published: December 24, 2019

\begin{abstract}
Information on food composition is of great importance for scientists and professionals working in the fields of nutrition and public health. The most apparent role of food composition is to provide the basis for dietary assessment and the formulation of healthier diets. Ready meals and food served in canteens are increasingly included in this approach considering their contribution to daily nutrition. There have been no studies that presented the nutritional values of some traditional Syrian sweets. This study was the first study to shed some lights about the nutritional facts of the traditional Syrian sweets. Seventeen different traditional Syrian sweets both regular calorie content (regular where sucrose was used as sweetener) and reduced calorie content (diet as Aspartame sweetener was used) were analyzed for Moisture, Ash, Carbohydrates, Protein and Fat content and finally calorie density per $100 \mathrm{~g}$ was calculated. The study also measured the calorie content of few sweets which we did not find diet ones similar to them. The results have shown that Syrian sweets in general are very calorie dense foods due to their high content of sugar, fat and other sweeteners such as honey and (high fructose corn Syrup (HFCS). The calorie density ranges from $347.5 \mathrm{Kcal}$ to $516.2 \mathrm{Kcal} / 100 \mathrm{~g}$ serving for diet sweets and $372.8 \mathrm{Kcal}$ to $532.2 \mathrm{Kcal} / 100 \mathrm{~g}$ serving for regular sweets. Protein ranged from $5.6 \mathrm{~g}$ to $18.4 \mathrm{~g}$ and fat from 5.5 to $29.8 \mathrm{~g} / 100 \mathrm{~g}$ serving.
\end{abstract}

Keywords: Syrian Sweets, CHO, Protein, Fat, Baklavah, Mamoul, Kunafeh, Barazek

\section{Introduction}

Knowledge of the nutrient content of foods is essential for many types of nutrition research and applied nutrition projects, including the interpretation of food consumption studies, the nutritional assessment of food supplies, and the planning of nutritionally adequate diets. Appropriate nutrient data bases are not always readily available for these activities. Food products require analysis as part of a quality management program throughout the development process, production, and after a product is in the markets. The chemical composition and physical properties of foods are used to determine the nutritive value, functional characteristics, and acceptability of the food product [1].

Providing the necessary data for the estimation of the intake of nutrients and other food components is still one of the major applications of Food Composition Data. Although it is theoretically possible to analyze directly the nutrient content of the consumed food, this is rarely carried out and is not applicable to large-scale assessments required for representative national nutrition surveys. However, different FCDBs may differ strongly from each other with regard to the nutrients they include $[2,3]$. Furthermore, it is not always possible to know about the provenance of a certain nutrient in composite foods as in the case of sugar, for instance, wherein the distinction between naturally occurring and added monoand disaccharides is rather difficult in a mixed diet. However, the content of certain critical nutrients such as added sugars, saturated fatty acids or salt is often used as an indicator of the healthiness of a diet $[4,5]$.

Food analysis tables help in translating nutrient-based recommendations into a form that is more applicable by consumers. They also have an important role when it comes to behavioral modifications that are considered a major means for the prevention of overweight and lifestyle- 
associate health problems. Although recommendations generally refer to food groups as a whole, information on the nutritional quality of individual foods is needed in order to compose a diet designed to meet specific requirements [6].

Besides indicating the nutrient contents by weight unit or portion on food packages, rating systems allowing an easy and rapid appraisal of the product, thus facilitating consumer choices, have been proposed. Among these, the traffic light system has been intensely debated, being particularly popular in the United Kingdom Labelling is increasingly considered as a tool to educate consumers to make healthier food choices. Simple front-of- package labels appear better suited to this purpose by helping consumers in their decision taking [7]. Indeed, despite some controversies, use of labels can have a beneficial influence on food choices $[8,9]$.

A special application of FCDB to diet composition is the planning of nutrition as part of a therapy. Well-known examples of diseases that require avoidance or accurate monitoring of certain nutrients include diabetes mellitus and dyslipidaemia. Although data on total carbohydrate and fat contents and major fatty acid classes are widely available, there is less information on other components with pathological relevance such as fructose, lactose or various amino acids, gluten or antigens. The importance of reliable data on food composition for therapeutic diets was recognized long ago and, for McCance, it was the main reason for compiling his database which, in its updated form, is still in use in the United Kingdom [10].

However, so far, most FCDBs do not encompass these data or only for some foods [11]. In addition, their concentration in foods is subject to a high variability depending on plant variety, cultivation and geographical conditions $[12,13]$. On the other hand, data on potentially harmful food components such as pesticides, contaminants or by-products of food processing, such as trans-fatty acids or acrylamide, are also important when making nutritional recommendations, providing the basis for the estimation of exposure and risk assessment [14]. They also provide the basis for recipe reformulation and modifications of production methods aimed at reducing the amount present in food [15]. In addition, completing missing values for specific compounds is important to reduce the risk of underestimating exposure that can arise from designating a missing value as null [16].

The process of making a diet version of a food usually requires finding an acceptable low calorie substitute for some high calorie ingredient. In some snacks, the food may be baked instead of fried thus reducing the calories. In other cases, low fat ingredients may be used as fat substitutes [17].

Another technique relies on the intentional addition of other reduced-calorie ingredients, such as resistant starch or dietary fiber, to replace part of the flour and achieve a more significant caloric reduction. [18]. In this study, we tried to find out if there are foods which had been labeled as diet in our local markets and to determine the difference between those two types with regard to their calorie contents after measuring calories in each sample.

Sugars, syrups, molasses, sugar alcohol and honey are all classified as nutritive sweeteners which in addition to their sensation of sweetness, provide bulk energy value and at high concentrations could exhibit preservation action.

However, alternative non-nutritive sweeteners (artificial sweeteners) such as saccharin, aspartame, acesulfame-k and cyclamate are sweetening substances which provide an adequate degree of sweetness to justify their use but they do not utilize in energy metabolism as sucrose [19].

The alternative sweeteners may be divided into two broad classes, namely those with a sweetening effect similar to sucrose-bulk sweeteners, and the intense sweeteners. It is of important to refer to the relationship of nutritive sweeteners and obesity [20]. The basic cause of overweight is an excess consumption of calories regardless of their source. For those who wish to lose weight, some form of caloric restriction is necessary. Cane and beet sugars accounted in 1982 about $96 \%$ of the world's production of caloric sweeteners and the high fructose corn syrup accounted (HFCS) for the remainder. In United States, HFCS constitutes a large portion of the corn sweetener market. Nutritive and non-nutritive sweeteners, such as aspartame and saccharin, have however become increasingly recognized by consumers for their low or non caloric attributes. United States statistics for 1984 show that within six years consumption trends for non caloric sweeteners were increased. This data, based on the sweetness equivalence to sucrose, highlight the trend of the sweetener market [21].

\section{Materials and Methods}

\subsection{Participants}

The study examined 17 traditional Syrian sweets which have been classified into 2 groups according to the type of sweetener used:

Group I: Regular sweets. Sucrose was used as sweetener.

Group II: Diet sweets. Aspartame was used as sweetener.

The study estimated the energy content of the sweets' samples by chemical analysis. Comparisons were made between Regular and Diet sweets of 11 different types of traditional Syrian sweets which have been purchased from the local market in Damascus, Syria. The performed analysis was; moisture $\%$, ash $\%$, fat $\%$, protein $\%, \mathrm{CHO} \%$ and then their calories were calculated in serving size of $100 \mathrm{~g}$ of the sweet sample.

Table 1 shows the types of traditional Syrian sweets that have been used in the study.

Table 1. Name of the traditional Syrian sweets in the study.

\begin{tabular}{lll}
\hline Name & Type of sweets & Picture \\
\hline Kol-Washkor & Diet & Regular \\
& Diet & \\
Baklavah & Regular & \\
\hline
\end{tabular}




\begin{tabular}{lll}
\hline Name & Type of sweets \\
\hline \multirow{3}{*}{ Bokaj } & Diet \\
Mabromeh & Regular & Diet \\
Regular & Diet \\
Kunafeh Nabelsiah & Regular \\
Kunafeh Madlouka & Diet \\
& Regular \\
Nut Mamoul & Diet \\
Regular & Diet \\
Pistachio Mamoul & Regular \\
Date Mamoul & Diet \\
& Regular \\
Awameh & Diet \\
& Regular \\
Nammora & Diet \\
& Regular
\end{tabular}

\subsection{Chemical Analysis}

Chemical analysis was performed for each sample and repeated 3 times, according to (AOAC, 2002) [22].

\subsubsection{Moisture Determination}

One of the most fundamental and important analytical procedures that can be performed on a food product are an assay of the amount of moisture.

Three grams were weighed into steel plate placed in forced draft oven for 3 hours at $105^{\circ} \mathrm{C}$ depending on the food sample and it's pretreatment.

$$
\begin{gathered}
\text { Moisture } \%=\frac{\text { Weight of wet sample }- \text { wt of dry sample }}{\text { Weight of wet sample }} \times 100 \\
\text { Total solids } \%=\frac{\text { Weight of dry sample }}{\text { Weight of wet sample }} \times 100
\end{gathered}
$$

\subsubsection{Ash Determination}

Ash refers to the inorganic residue remaining after either ignition or complete oxidation of organic matter in food stuff.

Five grams were weighed into porcelain crucibles then placed in the muffle furnace for 5 hours at $550^{\circ} \mathrm{C}$.
The ash content is calculated as follows:

Ash $\%=\frac{\text { Weight after ashing }- \text { weight of crucible }}{\text { Original sample wt } \times \text { dry matter coefficient }} \times 100$

Where: dry matter coefficient $=\%$ solids $/ 100$

\subsubsection{Fat Analysis: By Soxhlet Method}

It is semi continuous solvent extraction. The solvent builds up in the extraction chamber for 5-10 min and completely surround the sample, then siphons back to the boiling flask.

This method provides a soaking effect of the sample and does not cause channeling. Seven grams were weighed into extraction thimble then covered with glass wool.

Fat content is measured by weight loss of the sample or by weight fat removed.

\subsubsection{Protein Analysis: (Kjeldahel Method)}

In the Kjeldahel procedure, proteins and other organic food components in a one gram of sample are digested with sulfuric acid in the presents of catalysts.

The total organic nitrogen is converted to ammonium sulfate. The digest is neutralized with alkali and distilled into a boric acid solution.

The borate inions formed are titrated with standardized acid, which is converted to nitrogen in the sample.

The results of analysis represent the protein content of the food since nitrogen also comes from non protein components.

\subsubsection{Carbohydrates: (By Difference)}

$$
\begin{gathered}
\text { Carbohydrates }=100-(\% \text { protein }+\% \text { fat }+\% \text { ash }+\% \\
\text { moisture })
\end{gathered}
$$

After this chemical analysis, the bomb calorimeter was performed by instrument IKA calorimeter measurement C2000, Germany.

Calorie content was calculated by adding the amount of calories obtained from $\mathrm{CHO}$, protein and fat after multiplying the amount of $\mathrm{CHO}$ and protein in grams by 4 and the amount of fat in grams by 9 .

\begin{tabular}{|c|c|c|c|c|c|c|c|}
\hline Name of sweet & Type & Moisture (\%) & Ash (\%) & Fat (\%) & Protein (\%) & CHO (\%) & Calorie per $100 \mathrm{~g}$ \\
\hline \multirow{2}{*}{ Kol washkor } & $\mathrm{D}$ & $19.3 \pm 0.04$ & $0.7 \pm 0.07$ & $5.5 \pm 0.05$ & $5.6 \pm 0.42$ & $68.9 \pm 0.36$ & $347.5 \pm 20.2$ \\
\hline & $\mathrm{R}$ & $16.6 \pm 0.05$ & $0.7 \pm 0.09$ & $18.6 \pm 0.23$ & $8.0 \pm 0.81$ & $56.1 \pm 0.60$ & $428.8 \pm 25.3$ \\
\hline Baklavah & $\mathrm{R}$ & $16.3 \pm 0.21$ & $0.5 \pm 0.10$ & $12.3 \pm 1.60$ & $7.4 \pm 0.26$ & $63.5 \pm 1.61$ & $394.3 \pm 19.9$ \\
\hline \multirow{2}{*}{ Bokaj } & $\mathrm{D}$ & $9.2 \pm 0.04$ & $0.6 \pm 0.04$ & $21.3 \pm 0.78$ & $8.3 \pm 0.17$ & $60.6 \pm 0.85$ & $396.2 \pm 22.6$ \\
\hline & $\mathrm{R}$ & $7.9 \pm 0.04$ & $0.6 \pm 0.05$ & $18.5 \pm 1.30$ & $8.7 \pm 0.49$ & $64.3 \pm 1.63$ & $458.5 \pm 26.1$ \\
\hline \multirow{2}{*}{ Mabromeh } & $\mathrm{D}$ & $14 \pm 0.05$ & $1.5 \pm 0.05$ & $12.6 \pm 0.47$ & $14.5 \pm 0.41$ & $57.4 \pm 0.63$ & $401 \pm 25.3$ \\
\hline & $\mathrm{R}$ & $14.2 \pm 0.03$ & $1.3 \pm 0.06$ & $15.1 \pm 0.42$ & $9.7 \pm 0.45$ & $59.7 \pm 0.76$ & $413.5 \pm 26.9$ \\
\hline
\end{tabular}

\section{Results and Discussion}

The results obtained from this study are shown in table 2.

Table 2. Chemical analysis and calorie density of different types of Syrian sweets. 


\begin{tabular}{|c|c|c|c|c|c|c|c|}
\hline Name of sweet & Type & Moisture (\%) & Ash (\%) & Fat (\%) & Protein (\%) & CHO (\%) & Calorie per $100 \mathrm{~g}$ \\
\hline \multirow{2}{*}{ Kunafeh Nabelsiah } & D & $15.30 \pm 0.23$ & $0.9 \pm 0.09$ & $18.1 \pm 0.45$ & $18.4 \pm 0.51$ & $46.9 \pm 0.91$ & $424.1 \pm 19.7$ \\
\hline & $\mathrm{R}$ & $15.09 \pm 0.19$ & $1.21 \pm 0.06$ & $19.7 \pm 0.65$ & $16.5 \pm 0.49$ & $47.5 \pm 1.01$ & $433.3 \pm 20.1$ \\
\hline \multirow{2}{*}{ Kunafeh Madlouka } & D & $23.11 \pm 0.38$ & $1.19 \pm 0.04$ & $15.4 \pm 0.46$ & $10.9 \pm 0.31$ & $49.4 \pm 0.97$ & $379.8 \pm 16.3$ \\
\hline & $\mathrm{R}$ & $20 \pm 0.24$ & $1.3 \pm 0.06$ & $14.6 \pm 0.38$ & $10.2 \pm 0.21$ & $53.9 \pm 1.07$ & $387.8 \pm 16.9$ \\
\hline \multirow{2}{*}{ Nut Mamoul } & $\mathrm{D}$ & $9.3 \pm 0.05$ & $1.9 \pm 0.03$ & $19.4 \pm 0.44$ & $14.3 \pm 0.22$ & $54.1 \pm 1.09$ & $448.2 \pm 22.1$ \\
\hline & $\mathrm{R}$ & $4.1 \pm 0.12$ & $1.6 \pm 0.06$ & $20.2 \pm 0.46$ & $13.9 \pm 0.48$ & $60.2 \pm 1.2$ & $478.2 \pm 24.1$ \\
\hline \multirow{2}{*}{ Pistachio Mamoul } & $\mathrm{D}$ & $4.4 \pm 0.13$ & $0.8 \pm 0.01$ & $27.4 \pm 0.64$ & $16.1 \pm 0.63$ & $51.3 \pm 1.1$ & $516.2 \pm 26.7$ \\
\hline & $\mathrm{R}$ & $1.3 \pm 0.06$ & $1.4 \pm 0.02$ & $28.6 \pm 0.73$ & $17.4 \pm 0.77$ & $51.3 \pm 1.3$ & $532.2 \pm 27.4$ \\
\hline \multirow{2}{*}{ Date Mamoul } & D & $5.7 \pm 0.15$ & $0.7 \pm 0.01$ & $27.6 \pm 0.9$ & $9.7 \pm 0.81$ & $56.3 \pm 0.55$ & $512.4 \pm 20.3$ \\
\hline & $\mathrm{R}$ & $4.9 \pm 0.13$ & $1.1 \pm 0.01$ & $29.8 \pm 0.78$ & $11.4 \pm 0.92$ & $52.8 \pm 0.62$ & $525 \pm 22.2$ \\
\hline \multirow[b]{2}{*}{ Awameh } & D & $17.8 \pm 0.27$ & $0.6 \pm 0.01$ & $20.4 \pm 0.55$ & $7.2 \pm 0.12$ & $53 \pm 0.71$ & $424.4 \pm 24.2$ \\
\hline & $\mathrm{R}$ & $18.4 \pm 0.29$ & $0.9 \pm 0.04$ & $15.8 \pm 0.44$ & $7.9 \pm 0.14$ & $57 \pm 0.71$ & $401.8 \pm 19.9$ \\
\hline \multirow{2}{*}{ Nammoura } & $\mathrm{D}$ & $19.6 \pm 0.31$ & $1.1 \pm 0.05$ & $10.4 \pm 0.17$ & $6.1 \pm 0.11$ & $62.8 \pm 1.09$ & $369.2 \pm 17.6$ \\
\hline & $\mathrm{R}$ & $20.4 \pm 0.32$ & $0.9 \pm 0.02$ & $11.6 \pm 0.19$ & $7.6 \pm 0.12$ & $59.5 \pm 1.06$ & $372.8 \pm 20.1$ \\
\hline
\end{tabular}

Figure 1 shows the calorie content of the diet sweets. The highest Kcal/100 g was in Pistachio Mamoul (516.2Kcal/100 g) followed by date Mamoul $(512.4 \mathrm{Kcal} / 100 \mathrm{~g})$, Nut Mamoul (448.2 Kcal/100). Awameh and Kunafeh Nablsiah had almost similar calorie content in a serving size of $100 \mathrm{~g}$ (424.4 Kcal and 424.1 Kcal respectively).

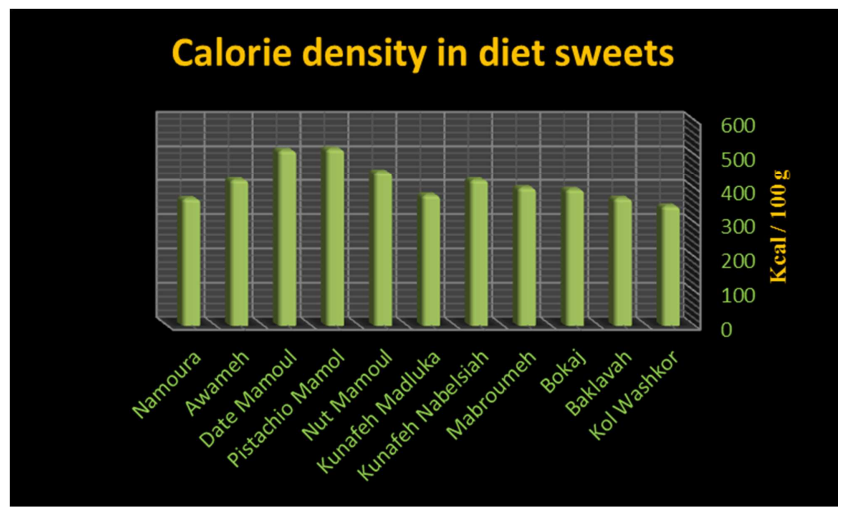

Figure 1. Calrie density in $100 \mathrm{~g}$ of diet swee.

Calorie density of the regular sweets are presented in Figure 2. Results have shown that Mamoul sweets (date and pistachio) had similar calorie and they were the highest in terms of Kcal/100 g. The lowest calorie content was Kunafeh Madluka (387.8 Kcal/100 g). The reason behind the decline in calorie content compared to other types of sweets was its high moisture content.

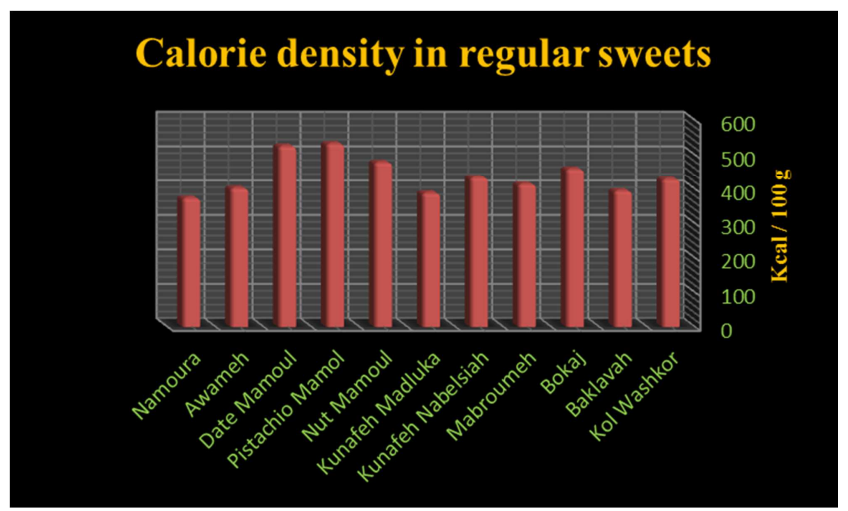

Figure 2. Calorie density in $100 \mathrm{~g}$ of regular sweet.

When compared the diet sweets in terms of their moisture content, the study found that Kunafeh Madluka has the highest moisture content $(23.11 \%)$ followed by Namoura and Kol Washkor (19.6\% and $19.3 \%$ respectively). The lowest moisture content was in Pistachio Mamoul. The lowest moisture content is found in different types of Mamouls (dates, Nut and Pistachio) and the same is shown in regular sweets. These may explained why these types of Mamouls are rich in calorie. The data are presented in figures 3 and 4.

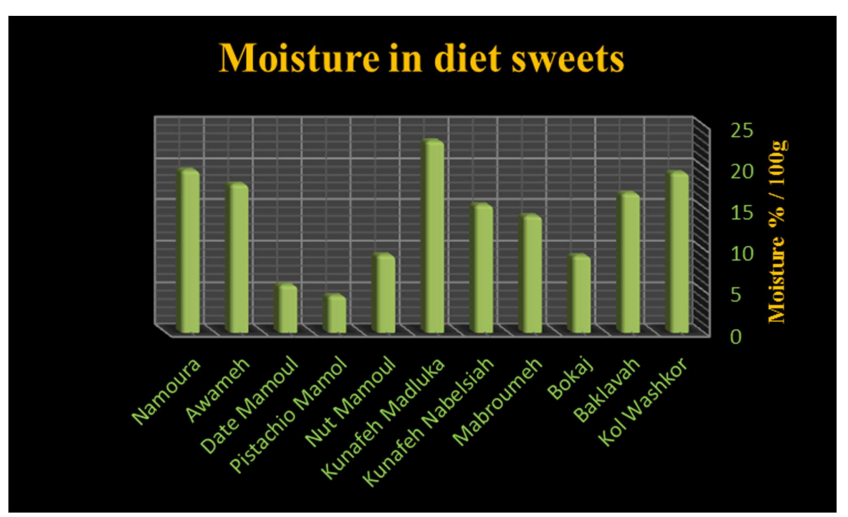

Figure 3. Moisture percentage in $100 \mathrm{~g}$ of diet sweet.

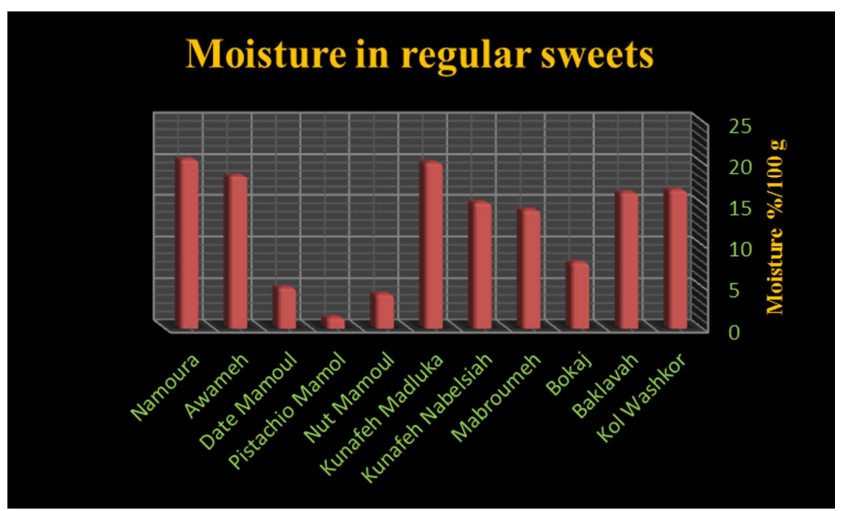

Figure 4. Moisture percentage in $100 \mathrm{~g}$ of regular sweet.

With regard to the ash content of the diet sweets, Nut Mamoul had the highest ash content (1.9 g/100 g serving) followed by Mabroumeh $(1.5 \mathrm{~g} / 100 \mathrm{~g})$. The lowest ash content was in Awameh and Bokaj (0.6 g/100 and $0.9 \mathrm{~g} / 100 \mathrm{~g}$ respectively). The data are presented in Figure 5.

Whereas, the highest ash content in the regular sweets was in Nut Mamouls (1.6 g/100 g serving) and the lowest wan in 
Baklavah $(0.1 \mathrm{~g} / 100 \mathrm{~g}$ serving $)$ as shown in figure 6 . The high protein content in Mamoul can be attributed to their nut content which is about $50 \%$ of their dry weight.

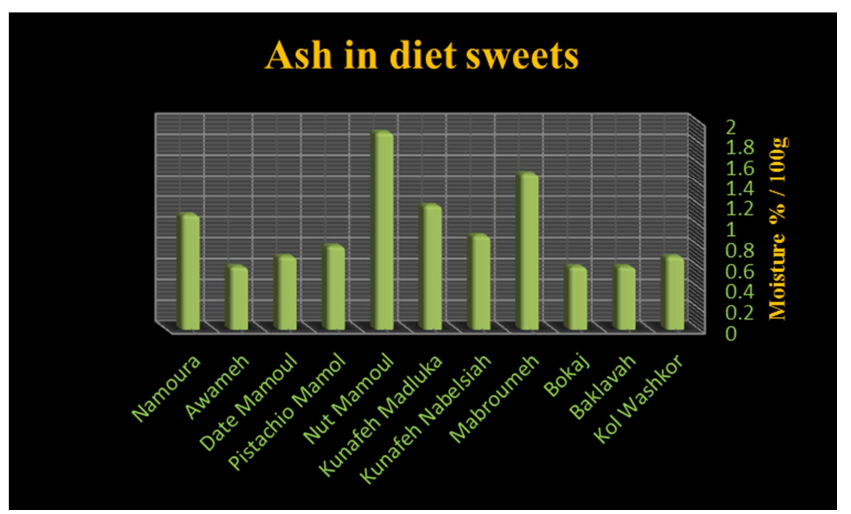

Figure 5. Ash percentage in $100 \mathrm{~g}$ of diet sweet.

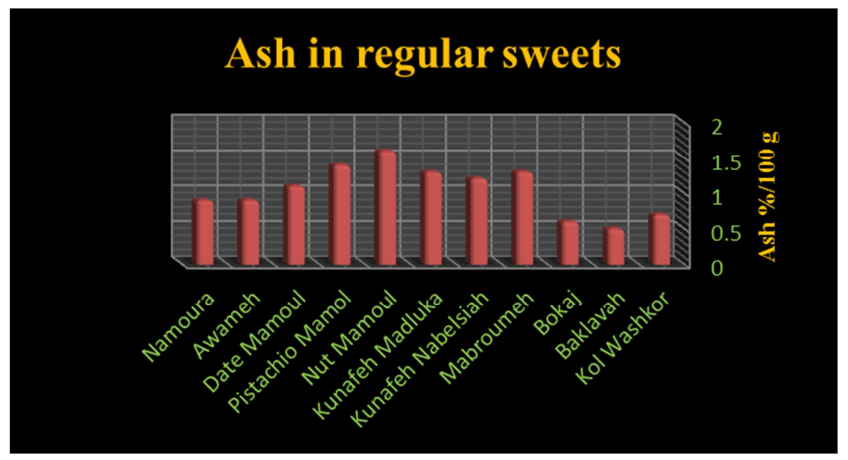

Figure 6. Ash percentage in $100 \mathrm{~g}$ of regular sweet.

Figure 7 shows the fat content in the diet sweets. The highest fat content of the sweet was in Nut and Pistachio Mamouls followed by Bokaj, Awameh and Kunafeh Nabulsiah. The variations in fat content is mainly due to the amount of butter oil used in making sweets and this could be an individual variations during preparation.

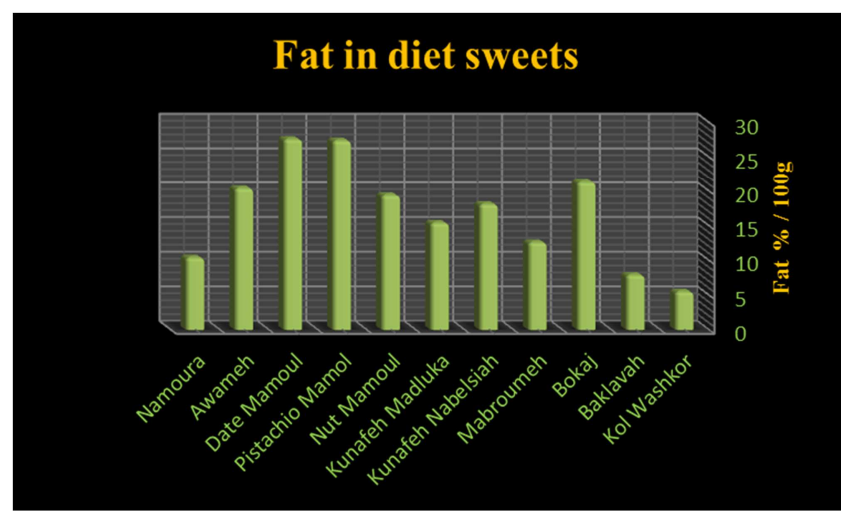

Figure 7. Fat percentage in $100 \mathrm{~g}$ of diet sweet.

In the regular sweets, the highest fat content was in Dates and Pistachio Mamouls (29.8 g/100 g and 28.6 $\mathrm{g} / 100 \mathrm{~g}$ respectively) and the lowest was in Baklava and Namoura (1.6 and $0.9 \mathrm{~g} / 100 \mathrm{~g}$ serving size) as shown in Figure 8 .

Syrian sweets are not rich in calories but in protein too.
Figure 9 shows the protein content of the diet sweets. The highest protein content was in Kunafeh Nablsiah (18.4 g/100 g) followed by Pistachio Mamoul (16.1 g) and Mabroumeh (14.5 g). The lowest content was in Kol Washkor (5.6 g/100 $\mathrm{g})$. The reason behind the result is the use of cheese in making Kunafeh Nablsiah.

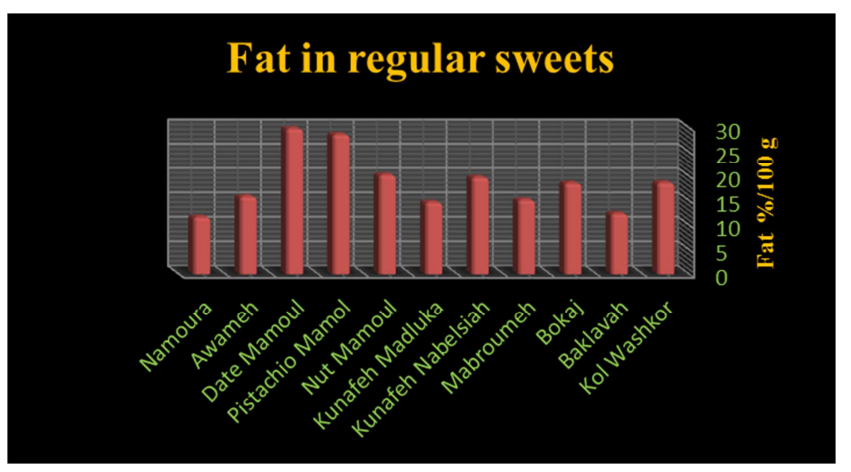

Figure 8. Fat percentage in $100 \mathrm{~g}$ of regular sweet.

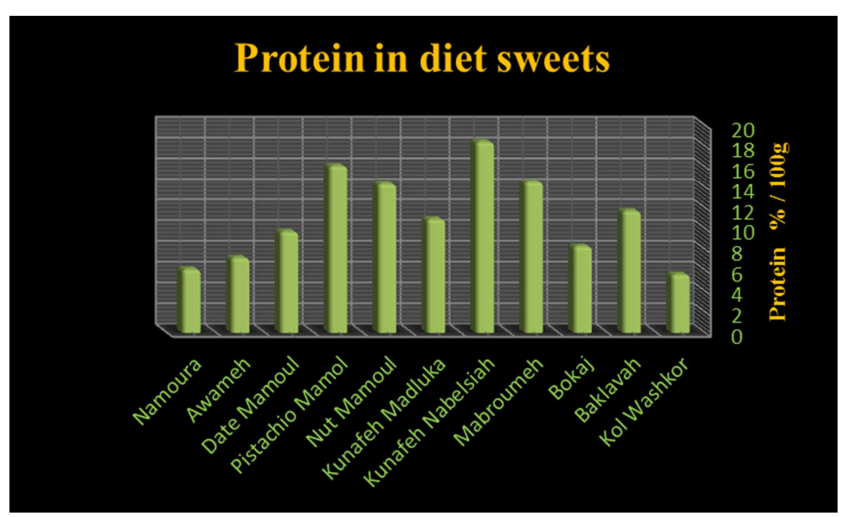

Figure 9. Protein percentage in $100 \mathrm{~g}$ of diet sweet.

The same applies to regular sweets to with regard to their protein content. Pistachio nut was the highest followed by Kunafeh Nablsiah and the lowest was in Namoura and Kol Washkor because they contained no cheese as shown in Figure 10.

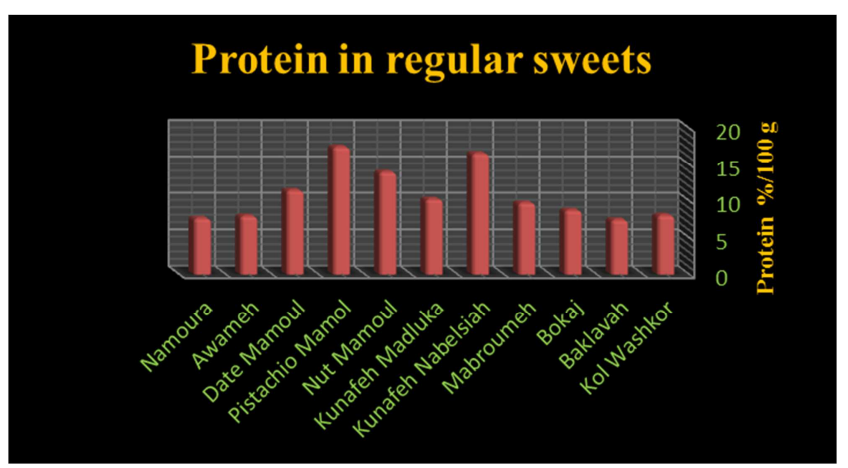

Figure 10. Protein percentage in $100 \mathrm{~g}$ of regular sweet.

When it comes to $\mathrm{CHO}$ content of the diet Syrian sweets, there was no difference between most sweets. $\mathrm{CHO}$ content ranges from $46.9 \mathrm{~g}$ to $68.9 \mathrm{~g}$ per $100 \mathrm{~g}$ serving size. The highest was in Kol Washkor (68.9 g/100) and lowest was in Kunafeh Nablsiah (46.9 g/100). 
Moisture content played an important role in increasing or decreasing $\mathrm{CHO}$ content. The same can be seen in regular sweets and their CHO content. The difference between different types of sweets was minimal as demonstrated in Figure 11 and Figure 12.

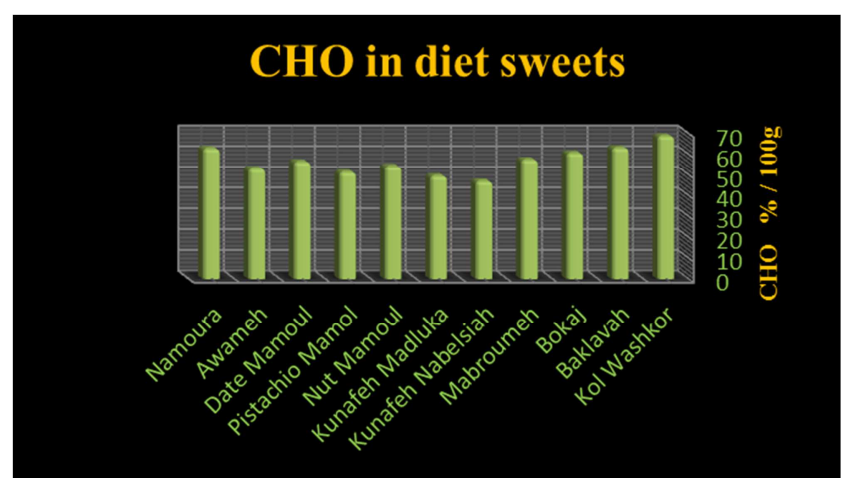

Figure 11. CHO percentage in $100 \mathrm{~g}$ of diet sweets.

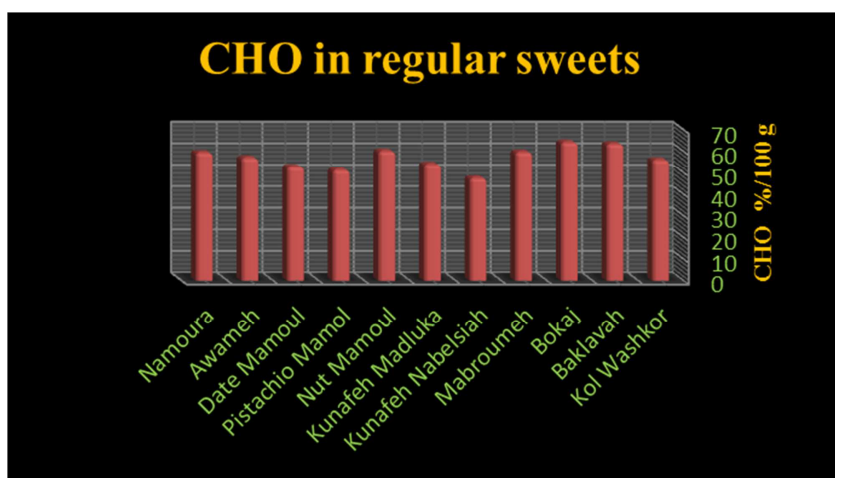

Figure 12. CHO percentage in $100 \mathrm{~g}$ of regular sweet.

The study has examined also other types of regular sweets only because it was difficult to find their version of diet sweets. The sweets were: Barazek, Ghoribah, Plain Kaak, Seasme Kaak, Halwa Bil Jibn, and Harriseh.

The chemical analysis of the sweets are shown in table 3.

Table 3. Chemical analysis of some other regular sweets.

\begin{tabular}{|c|c|c|c|c|c|c|c|}
\hline Name of sweet & Picture & Moisture (\%) & Ash (\%) & Fat (\%) & Protein (\%) & CHO (\%) & Kcal per $100 \mathrm{~g}$ \\
\hline Barazek & & $13.3 \pm 1.7^{\mathrm{c}}$ & $1.3 \pm 0.2^{\mathrm{c}}$ & $19.8 \pm 4.4^{\mathrm{b}}$ & $13.1 \pm 3.1^{\mathrm{b}}$ & $52.5 \pm 11.3^{\mathrm{f}}$ & $440.6 \pm 19.4^{\mathrm{b}}$ \\
\hline Ghoribah & & $12.6 \pm 2.1^{\mathrm{d}}$ & $1.9 \pm 0.3^{\mathrm{a}}$ & $21.6 \pm 4.7^{\mathrm{a}}$ & $9.1 \pm 2.6^{\mathrm{c}}$ & $54.8 \pm 11.7^{\mathrm{e}}$ & $450 \pm 20.1^{\mathrm{a}}$ \\
\hline Plain Kaak (bread stick) & & $8.6 \pm 1.2^{\mathrm{e}}$ & $1.4 \pm 0.2$ & $9.6 \pm 2.7^{\mathrm{d}}$ & $1.7 \pm 0.3^{\mathrm{e}}$ & $78.7 \pm 12.6^{\mathrm{a}}$ & $408 \pm 16.7^{\mathrm{d}}$ \\
\hline Sesame Kaak (bread stick) & & $6.2 \pm 0.9^{f}$ & $1.6 \pm 0.2^{\mathrm{b}}$ & $10.8 \pm 2.8^{\mathrm{c}}$ & $4.6 \pm 1.1^{\mathrm{d}}$ & $76.8 \pm 11.8^{b}$ & $422.8 \pm 19.1^{\mathrm{c}}$ \\
\hline Harriseh & & $15.7 \pm 1.9^{\mathrm{a}}$ & $1.3 \pm 0.08^{\mathrm{c}}$ & $8.2 \pm 1.1^{\mathrm{f}}$ & $1.1 \pm 0.04^{\mathrm{f}}$ & $73.7 \pm 10.2^{c}$ & $373 \pm 12.5^{\mathrm{f}}$ \\
\hline
\end{tabular}

Different letters denote significant difference $(\mathrm{P}<0.05)$.

When checking moisture percentage, Harrisah and Halwa Bil Jibn had the highest moisture content $(15.7 \mathrm{~g} / 100$ and $15.4 \mathrm{~g} / 100 \mathrm{~g}$ respectively) and the lowest were in Plain and sesame Kaak (8.6 and $6.2 \mathrm{~g} / 100 \mathrm{~g}$ ) as shown in Figure 13.

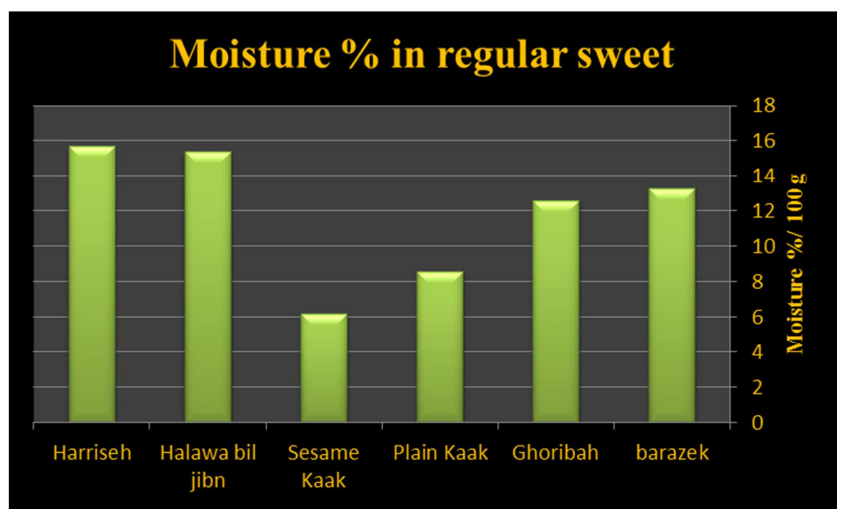

Figure 13. Moisture content in regular sweets.

Figure 14 and Figure 15, showed the CHO content and the calorie density of the regular sweets. Almost all sweets had similar content. The $\mathrm{CHO}$ content ranges from $55 \%$ to almost $80 \%$. The highest was plain and sesame Kaak followed by Harriseh. The calorie density of the regular sweets is very close to each other. The highest calorie density is found in Ghoribah and Barazek (450 g/110 g and $440 \mathrm{~g} / 100 \mathrm{~g})$ followed by seasame Kaak, plain Kaak and the lowest was in Halawa Bil Jibn and Harrisah. The reason behind increasing the calorie density in Ghoribah and Barazek is the low moisture content and having ingredients such as sesame and butter oil when making them.

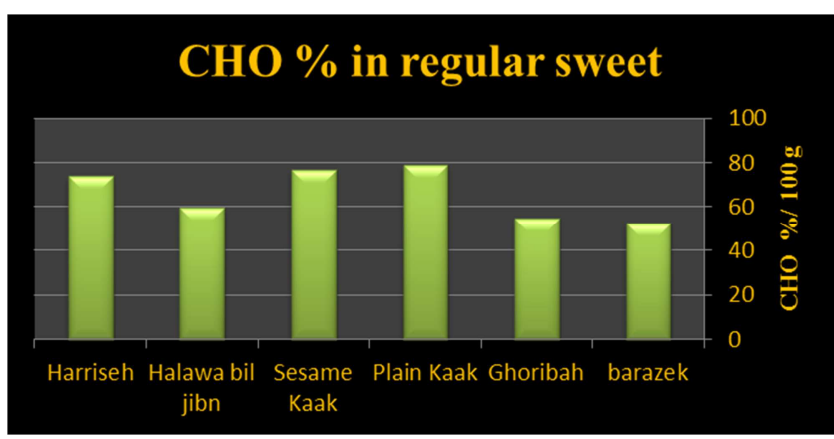

Figure 14. CHO content in regular sweets.

Figure 16 shows a comparison between diet and regular sweets. All sweets except Awameh, their diet version had less calorie content. This is due to use artificial sweeteners such as aspartame but in case of Awameh, the explanation of why 
diet Awameh had more calorie had several reasons. The best is the change of ingredients such as fat or the type of flour used in preparation.

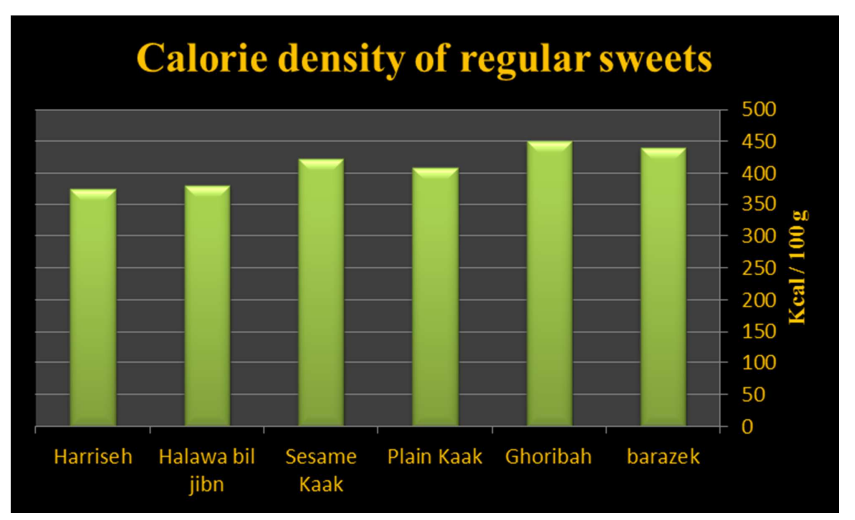

Figure 15. Calorie content of regular sweets.

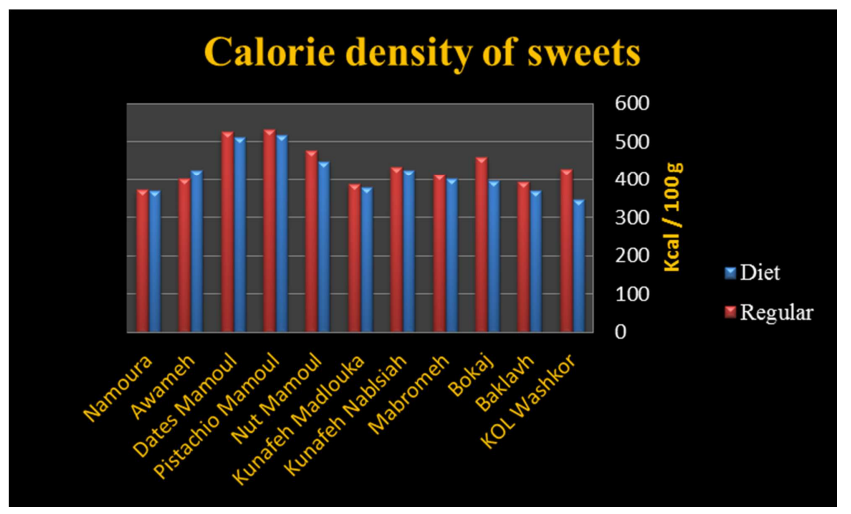

Figure 16. Comparison of calorie density between diet and regular sweets.

\section{Conclusion}

The results obtained from this study are not conclusive because in every region of Syria, there are some variations in the recipes during preparation of the sweets. These variations are reflected in the nutritive value of such sweets and their calorie content. Therefore, this study offered the first step towards appreciation of the nutritive value of the traditional Syrian sweets. The data are very helpful for diet professionals and for the public who are looking after their health.

The traditional Syrian sweets are very rich in nutrients such as fat, protein and sugars. They also contain high caloric values per serving (Kcal/100 g). People with compromised health status should always take into consideration these values as prevention of certain diseases such as diabetes. Especially for those who want to reduce weight or to maintain their body weight. Cholesterol problem is another issue as the tradition Syrian sweets are high in saturated fatty acids is recently trans- fats have been used to replace animal fats because they are cheaper but they can cause severe health problems. Consumers should be aware of this information.

\section{Recommendations}

As this study has shown that the Syrian sweets are rich in calories and other nutrients such as fat, protein and carbohydrates. People should be aware of what they eat especially in terms of how many calories in the serving size they eat. In addition to the amount of grams of fat in their sweet treat. Syrian sweets contain at least 3 serving size of $\mathrm{CHO}$ and sometimes around 4 which equals 45 to 50 grams of sugar per 100 grams of sweets. Being aware of these numbers, person can maintain his/her healthy weight and even can reduce it.

Knowing the fat amount will not only good for healthy weigh but for health heart. High fat intake mainly saturated fat and trans-fats are not good for heart health.

\section{Acknowledgements}

Authors would like to thank people who assisted in analyzing samples at both at $\mathrm{Al}$ Jazeera and $\mathrm{Al}$ Baath Universities and for their contribution towards this work.

\section{References}

[1] Greenfield, H. and Southgate, D. A. T. (2003) Food Composition Data 2nd Edition: Production, Management and Use. Elsevier Science Publishers, FAO, Rome.

[2] Nielsen, S. S. (2003). Food analysis. Third Edition, Springer, USA.

[3] Rameen Devi.; Sch J Agric Vet Sci., Aug-Sep 2015; 2 (4A): 304-311.

[4] Livingstone MB, Rennie KL. Added sugars and micronutrient dilution. Obes Rev. 2009 Mar; 10 Suppl 1: 34-40. doi: 10.1111/j.1467-789X.2008.00563.x.

[5] Matthew, A. F (2009). Energy content in a candy bar. Cal Poly University's Journal. 1132: 23-31.

[6] Lobstein T1, Davies S. Defining and labelling 'healthy' and 'unhealthy' food. Public Health Nutr. 2009 Mar; 12 (3): 33140.

[7] Grunert and Wills, 2007. A review of European research on consumer response to nutrition information on food labelsJournal of Public Health volume 15, Issue 5, pp 385399.

[8] Pietinen P, Paturi M, Reinivuo H, Tapanainen H, Valsta LM. FINDIET 2007 Survey: energy and nutrient intakes. Public Health Nutr. 2010 Jun; 13 (6A): 920-4. doi: $10.1017 / \mathrm{S} 1368980010001102$.

[9] Variyam JN. Do nutrition labels improve dietary outcomes? Health Econ. 2008 Jun; 17 (6): 695-708.

[10] Meirelles, A. and Handwerk, R. (2009). Dietary Fructose and Glucose Differentially Affect Lipid. The Journal of Nutrition 139: 1257S-1262S.

[11] Zimmerman TP, Hull SG, McNutt S, et al. Challenges in converting an interviewer-administered food probe database to self-administration in the National Cancer Institute Automated Self-administered 24-Hour Recall (ASA24). J Food Compost Anal. 2009; 22 (Supplement 1): S48-S51. doi: 10.1016/j.jfca.2009.02.003. 
[12] Tanu J, KGrove. International Journal of Health Sciences \& Research. Vol. 5; Issue: 5; May 2015.

[13] Vincenzo, Fogliano. Giuseppe, Maiani and Giovanni, Quaglia. Seasonal variations in antioxidant components of cherry tomatoes (Lycopersicon esculentum cv. Naomi F1) Journal of Food Composition and Analysis Volume 19, Issue 1, February 2006, Pages 11-19.

[14] Jakszyn P, et al. Development of a food database of nitrosamines, heterocyclic amines, and polycyclic aromatic hydrocarbons. J Nutr. 2004.

[15] Birlouez-Aragon I, Saavedra G, Tessier FJ, Galinier A, AitAmeur L, Lacoste F, Niamba CN, Alt N, Somoza V, Lecerf JM A diet based on high-heat-treated foods promotes risk factors for diabetes mellitus and cardiovascular diseases. Am J Clin Nutr. 2010 May; 91 (5): 1220-6. doi: 10.3945/ajcn.2009.28737. Epub 2010 Mar 24.

[16] Merchant AT1, Dehghan M. Food composition database development for between country comparisons. Nutr J. 2006 Jan 19; 5: 2.

[17] Grenby, T. H. (1991). Intense sweeteners for the food industry. An overview. Trends in food Sci. and Tech. 2 (1): 2-6.

[18] Branen, A. L.; Davidson, P. M. and Saminene, G. (1990). Food Additives, Sweeteners. Marcel Dekker, INC, N. Y. and Basel, Chapter 8, 297-323.

[19] Giese, J. H. (1993). Alternative sweeteners and bulking agents. Food Technology. 47 (1): 114-126.

[20] Franta, R. and Beck, B. (1986). Sweeteners. Alternative to cane and beet sugar. J. Food Techno., 40 (1): 116-128.

[21] Lecos, C. W. (1985). Sweetness minus calories- controversy. FDA Consumer, 19 (2): 18.

[22] A. O. A. C. (2002). "Official Methods of Analysis", 17th ed. Association of Official Analytical Chemists, Published by the Association of Official Analytical Chemists, Inc. USA. 